\title{
SUNDEW CHEMISTRY AND EMERGENCE UPDATES
}

JAN SCHLAUER • Zwischenstr. 11 • D-60594 Frankfurt/Main•Germany • jan@carnivorousplants.org Siegfried R. H. Hartmeyer, Irmgard Hartmeyer • Wittlinger Str. 5 • D-79576 Weil am Rhein

- Germany•s.hartmeyer@t-online.de

Holger Hennern, AnJa HenNern • Marktstr. 15 • D-44866 Bochum• Germany • hennern@arcor.de

Keywords: Drosera, metabolism, phytochemistry, naphthoquinones, chemotaxonomy, micromorphology, emergences.

\section{Introduction}

Plumbagin and 7-methyljuglone are characteristic acetogenic (= derived from acetic acid) naphthoquinones (see Scheme 1) that allow a chemotaxonomic delimitation and the distinction between sundew (Drosera L.) species or species groups (Zenk et al. 1969; Durand \& Zenk 1974; Culham \& Gornall 1994; Schlauer et al. 2005). This has recently (Schlauer et al. 2017) been applied to several Australian species in Drosera sections Arachnopus Planch. (the "D. indica L. complex") and Coelophylla Planch. (D. glanduligera Lehm.). By extending these studies to further accessions and species, some new and interesting insights into the chemical diversity of the genus were gained. In addition, the characteristic leaf and stem emergences of all examined Arachnopus species are featured in detail by microscopy images.

Materials and Methods

All plants used in the present study were raised from seed. The geographic origin of all accessions was traced as far as possible (see Table 1). They were cultivated, harvested, and investigated under the same conditions applying the same methods as reported previously (Schlauer et al. 2017). Further accessions of several species already mentioned in that publication and of additional species were investigated in order to confirm their chemical characterization and/or to yield new results.

Mature (flowering) specimens of seven representatives of D. section Arachnopus were investigated for leaf and stem surface emergences by microscopy with a WILOSKOP F Zoom (Hund Wetzlar) with fiber light source FLQ $150 \mathrm{M}$ (Hund Wetzlar) including swan neck fiber optics and a CMOS-camera UI1460LE-C (IDS Imaging Development Systems GmbH). The obtained images were enhanced for contrast and definition by MAGIX Foto \& Grafik Designer (MAGIX Software $\mathrm{GmbH}$ ) and EDIUS Workgroup 8.32 (Grass Valley K.K.).

\section{Results}

Naphthoquinones were detected in all investigated samples as summarized in Table 1.

Characteristic emergences for several species of D. section Arachnopus are shown in Figures $1-8$. 


\begin{tabular}{|c|c|c|c|c|}
\hline Section & Species & Accessions & Provenance & Quinone(s) \\
\hline \multirow[t]{8}{*}{ Arachnopus } & D. aurantiaca* & 1 & $\begin{array}{l}\text { Kimberleys, } \\
\text { Australia }\end{array}$ & 7-Methyljuglone \\
\hline & D. cucullata & 9 & $\begin{array}{l}\text { Kimberleys, } \\
\text { Australia }\end{array}$ & Plumbagin \\
\hline & \multirow[t]{2}{*}{ D. finlaysoniana } & 4 & $\begin{array}{l}\text { Kimberleys, } \\
\text { Australia }\end{array}$ & Plumbagin \\
\hline & & 2 & $\begin{array}{l}\text { Queensland, } \\
\text { Australia }\end{array}$ & Plumbagin \\
\hline & $\begin{array}{l}D . \\
\text { hartmeyerorum }\end{array}$ & 2 & $\begin{array}{l}\text { Kimberleys, } \\
\text { Australia }\end{array}$ & 7-Methyljuglone \\
\hline & D. indica & 1 & Vietnam & $\begin{array}{l}\text { 7-Methyljuglone } \\
+ \text { Plumbagin }\end{array}$ \\
\hline & \multirow[t]{2}{*}{ D. serpens } & 3 & $\begin{array}{l}\text { Kimberleys, } \\
\text { Australia }\end{array}$ & Plumbagin \\
\hline & & 4 & $\begin{array}{l}\text { Queensland, } \\
\text { Australia }\end{array}$ & Plumbagin \\
\hline \multirow[t]{2}{*}{ Thelocalyx } & D. burmannii & 1 & Vietnam & 7-Methyljuglone \\
\hline & D. sessilifolia* & 1 & Brazil & 7-Methyljuglone \\
\hline
\end{tabular}

*Species investigated here for the first time. NB: Earlier reports on D. indica quinones did not necessarily deal with this but possibly with different species of D. sect. Arachnopus.

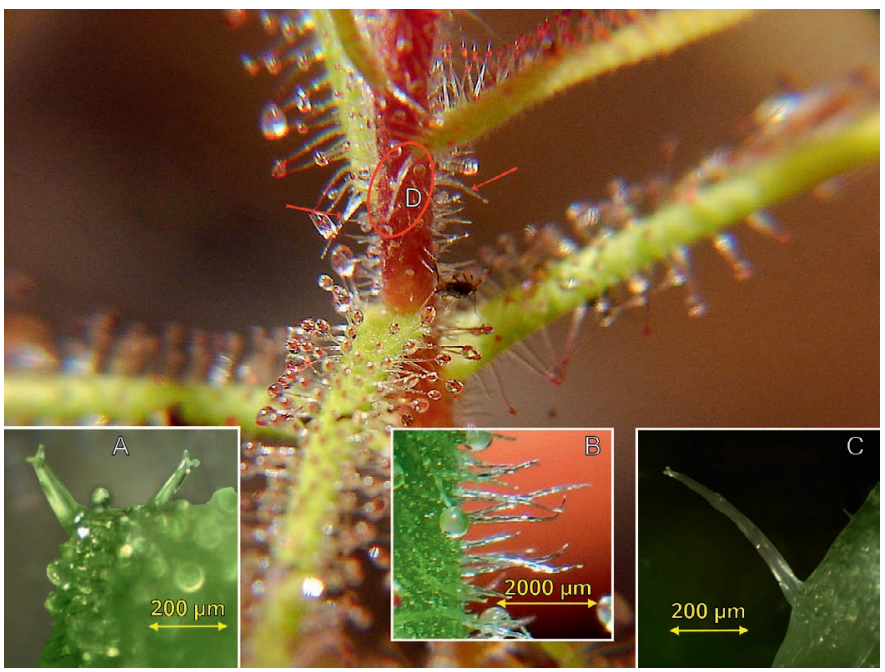

Figure 1: Drosera aquatica. Background: mature stem with leaf bases showing lateral "stipules" (actually emergences) at leaf bases (red arrows and oval); A: double-tipped cap emergences; B: elongated double-tipped caps ("hairs") and stalked glands on stem; C: elongated double-tipped cap at side of leaf base. 


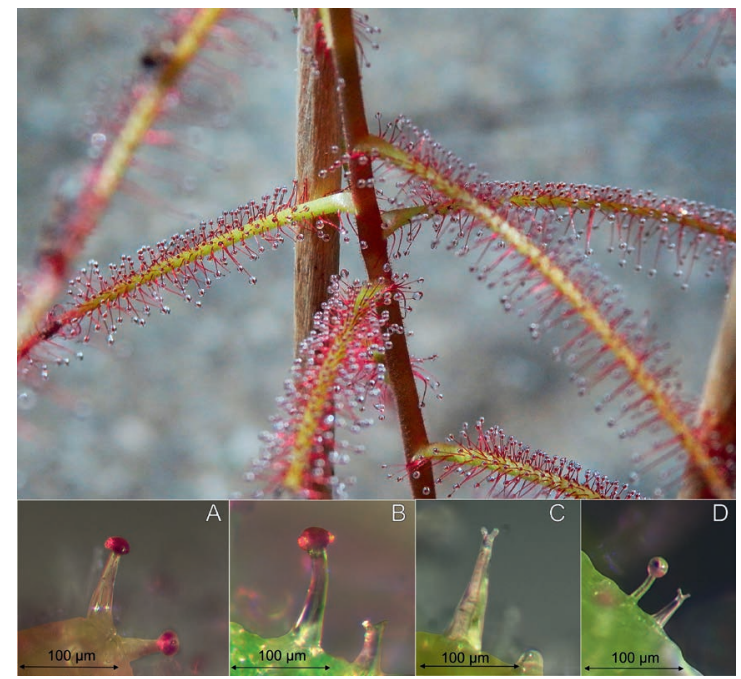

Figure 2: Drosera aurantiaca. Background: mature stem with leaf bases; A: mushroomshaped emergences; B: a small double-tipped cap emergence (right) and a longer mushroom-shaped stalked gland (left) with beginning excrescence (transition to bullshead shape?) on either side; C: long double-tipped cap (left) and stunted form (right); D: short stalked gland (left) and double-tipped cap (right).

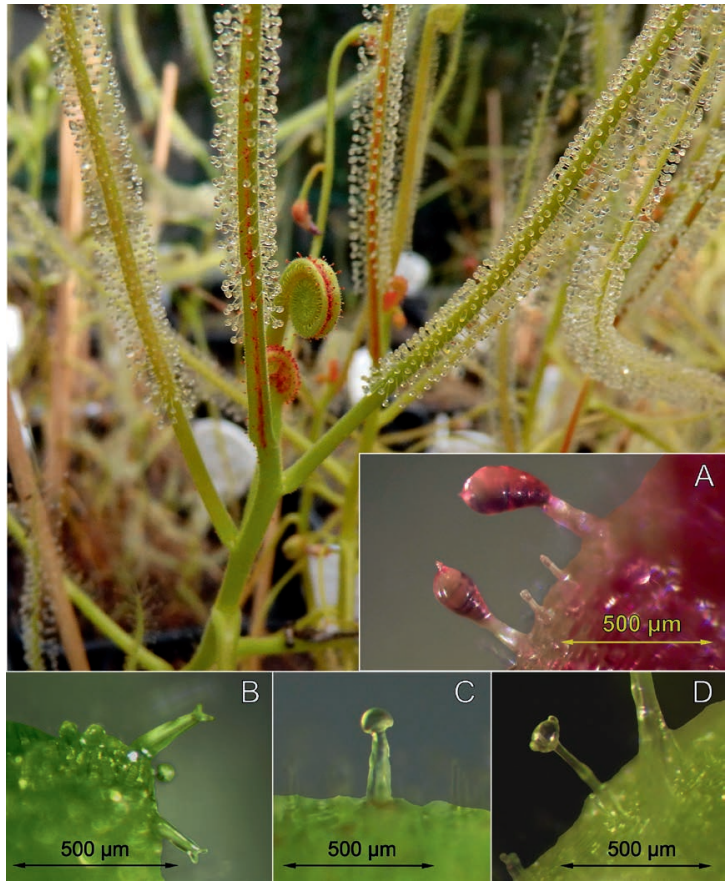

Figure 3: Drosera cucullata. Background: mature stem with leaf bases; A: insect- abdomenshaped emergences (large) and small double tipped caps with almost completely round head (center); B: double-tipped caps; C: mushroom-shaped emergence; D: mushroombulls-head transition and small double tipped cap (left). 


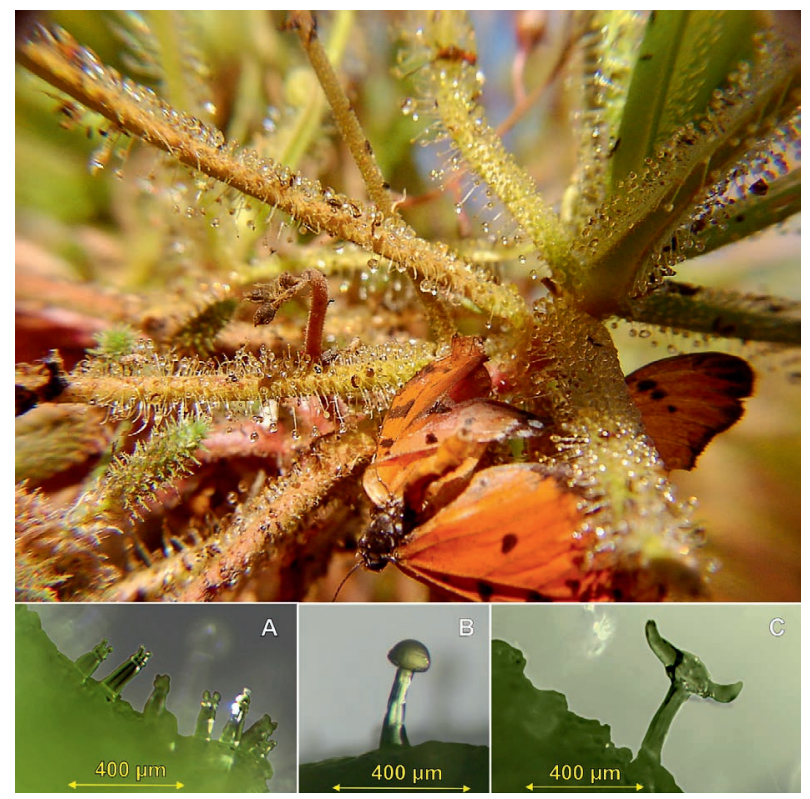

Figure 4: Drosera finlaysoniana. Background: mature stem with leaf bases; A: doubletipped caps; B: mushroom-shaped emergence; C: bulls-head with translucent center.

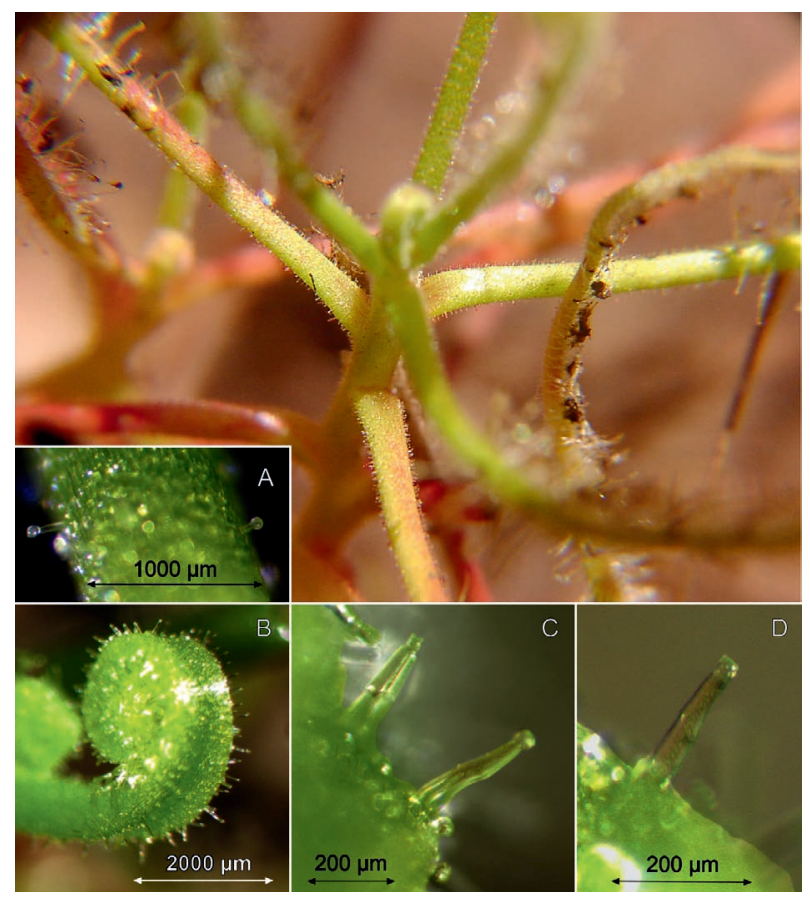

Figure 5: Drosera fragrans. Background: mature stem with leaf bases; A: stalked glands; $B$ : involute leaf bud viewed from abaxial side showing double-tipped caps; C: doubletipped caps; D: double-tipped cap with almost completely round head. 


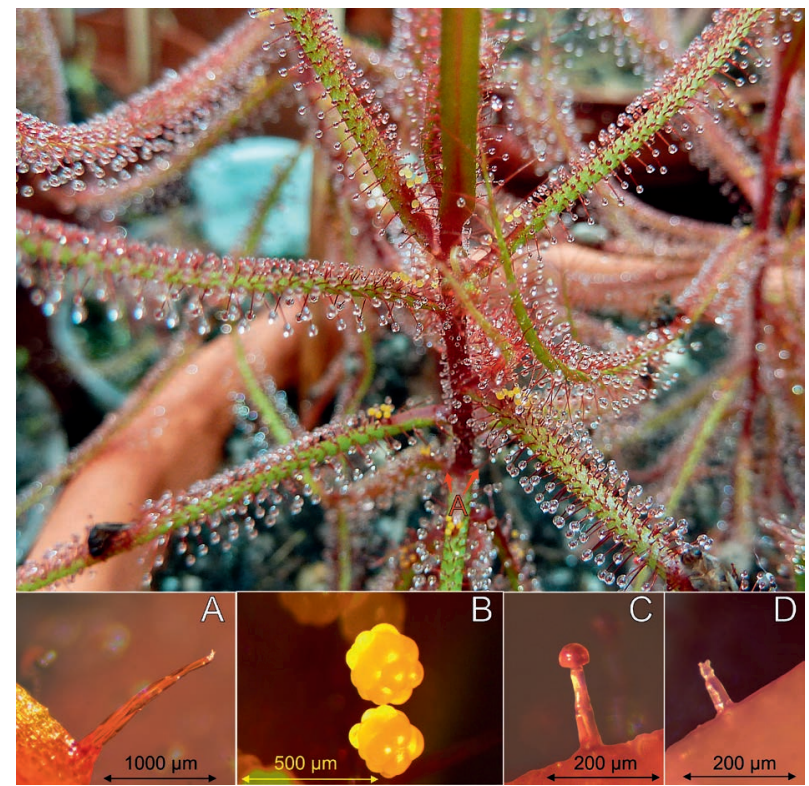

Figure 6: Drosera hartmeyerorum. Background: mature stem with leaf bases; A: doubletipped cap with elongated stalk at leaf bases (red arrows); B: moriform emergence showing giant cells; C: mushroom-emergence; D: double-tipped cap.

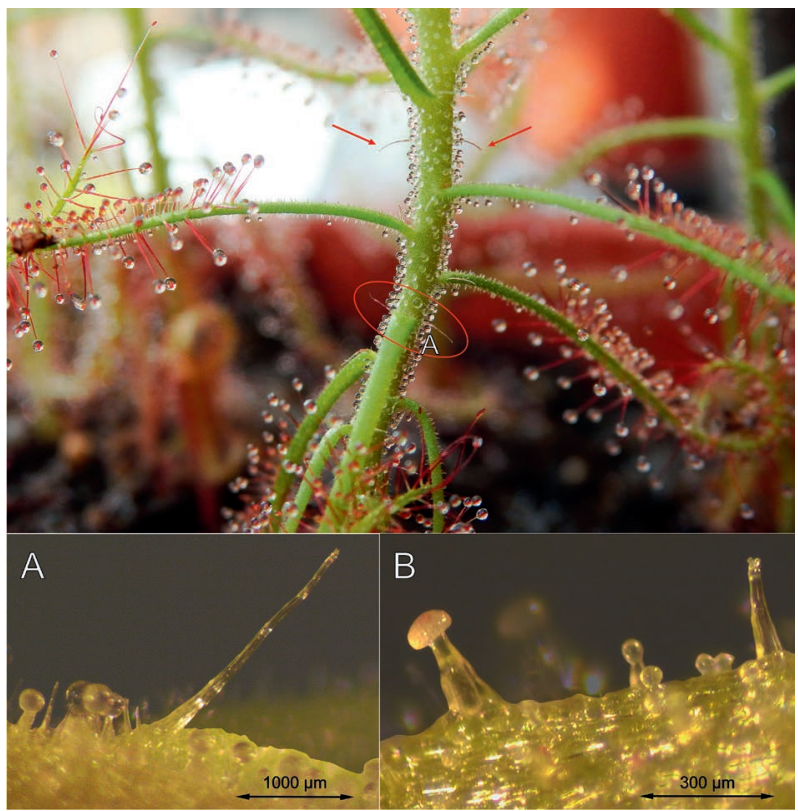

Figure 7: Drosera indica. Background: mature stem with leaf bases showing lateral "stipules" (actually emergences) at leaf bases (red arrows and oval); A: double-tipped cap with elongated stalk at leaf base with stalked glands and short double-tipped caps; B: mushroom-emergence (left), shorter stalked glands and medium sized double-tipped cap. 


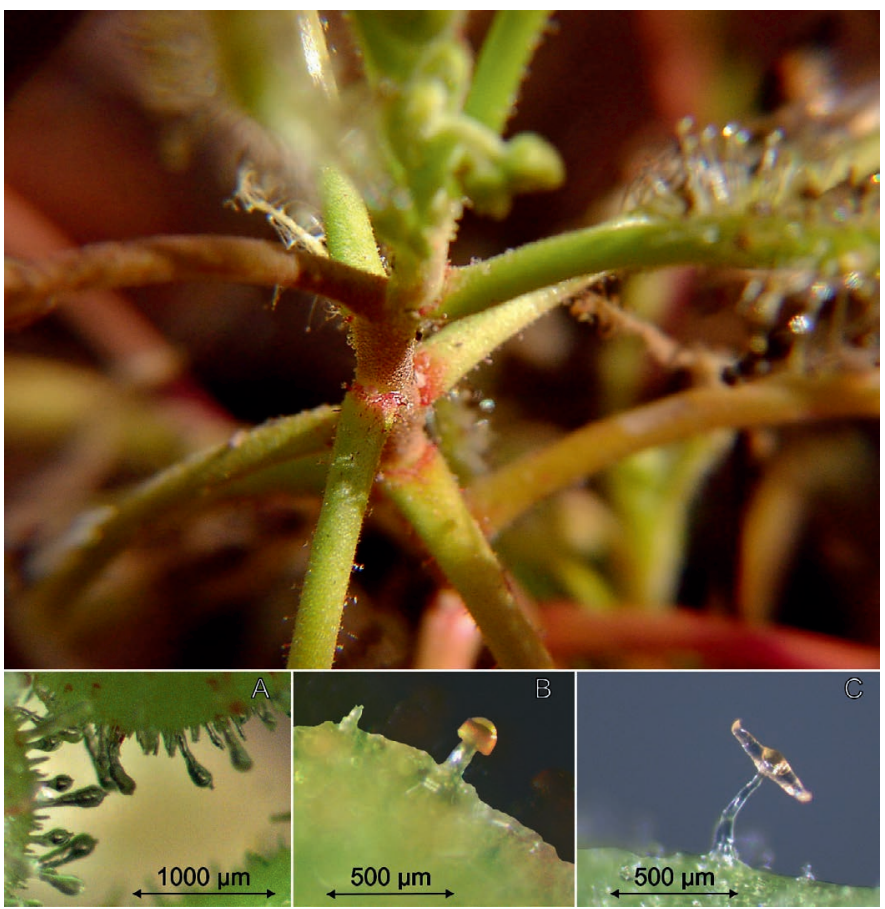

Figure 8: Drosera serpens. Background: mature stem with leaf bases; A: double-tipped caps (short) and insect-abdomen-emergences (long); B: bowler-hat-emergence (right) and double-tipped cap (left); C: bulls-head emergence with yellow center.

\section{Discussion}

The naphthoquinones detected in the investigated species of $D$. section Arachnopus confirm the chemical diversity as outlined previously (Schlauer et al. 2017). The constant chemism of the frequent species $D$. serpens Planch. and $D$. finlaysoniana Wall. ex Planch. across all investigated accessions demonstrates the reliability of quinones as chemotaxonomic markers.

Among species that lack distinct petioles (like e.g., D. aurantiaca Lowrie, D. aquatica Lowrie, or $D$. hartmeyerorum Schlauer), D. finlaysoniana is noteworthy as the only one known to contain plumbagin instead of 7-methyljuglone.

Most unusual is the detection of both plumbagin and 7-methyljuglone in $D$. indica s. str. So far both have only been found together in the same plant in hybridogenic taxa (Schlauer \& Fleischmann 2016). Within its whole range (from western tropical Africa to East Asia, including China and Japan) $D$. indica is so far known to come into contact with only two species of $D$. section Arachnopus (D. finlaysoniana and D. serpens), both known to contain plumbagin and not 7-methyljuglone, so no potential parent contributing the ability to form 7-methyljuglone can be postulated. Perhaps the formation of both quinones in $D$. indica is a rare case of loss of regioselectivity in the biosynthesis of these metabolites (possibly at the stage of formation of the tetralones, see Scheme 1).

The detection of 7-methyljuglone in both species of $D$. section Thelocalyx Planch. confirms previous reports for D. burmannii Vahl (Culham \& Gornall 1994) and underlines a close relationship between both species that is also expressed in a high degree of morphological overlap between them. 


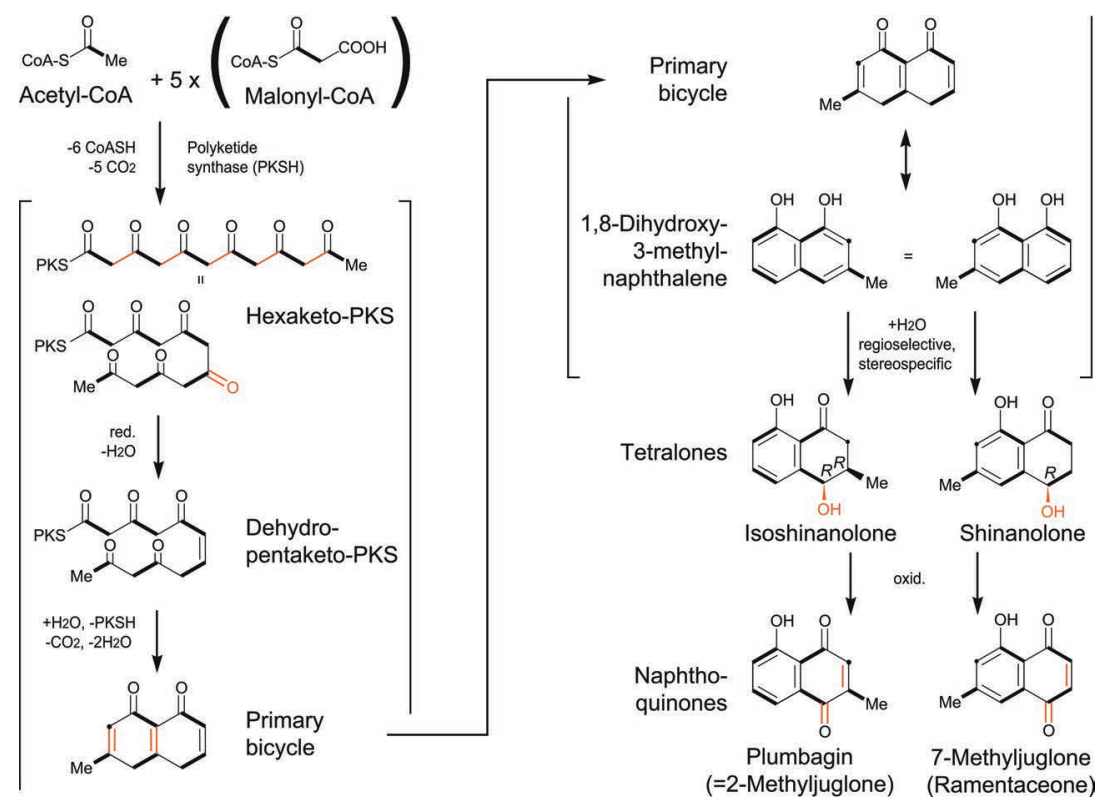

Scheme 1: Hypothetical biosynthesis of naphthoquinones in Drosera. Acetate-derived $\mathrm{C}_{2}$ units shown as bold lines, resulting $C_{1}$ units as filled circles.

Our results stand in sharp contrast to the purported presence of plumbagin in D. burmannii (Putalun et al. 2010), and we attribute this doubtful record to an inappropriate detection method (immunoassay without exclusion of cross-reactivity against 7-methyljuglone) in the latter study.

In contrast to (intrapetiolar) stipules that are leaf like outgrowths along the whole length of the dividing line between the upper (adaxial) surface of the leaves and the stem in Drosera, emergences have their base limited to a small area only a few cells in diameter on the surface of leaves or stems. By this definition and based on the fact that they are frequently terminated by two tips (like in the common double-tipped cap emergences), the structures previously described as stipules in $D$. sect. Arachnopus are identified as emergences here.

Acknowledgements: This work significantly benefitted from the generous donation of seeds by Gideon Lim, Selangor, Malaysia, for which we have the pleasure to express our gratitude.

\section{References}

Culham, A., and Gornall, R.J. 1994. The taxonomic significance of naphthoquinones in the Droseraceae. Biochem. Syst. Ecol. 22: 507-515.

Durand, R., and Zenk, M.H. 1974. The homogentisate ring-cleavage pathway in the biosynthesis of acetate-derived naphthoquinones of the Droseraceae. Phytochemistry 13: 1483-1492.

Putalun, W., Udomsin, O., Yusakul, G., Juengwatanatrakul, T., Sakamoto, S., and Tanaka, H. 2010. Enhanced plumbagin production from in vitro cultures of Drosera burmanii using elicitation. Biotechnol. Lett. 32: 721-724.

Schlauer, J., and Fleischmann, A. 2016. Chemical evidence for hybridity in Drosera (Droseraceae).

Biochem. Syst. Ecol. 66: 33-36. 
Schlauer, J., Hartmeyer, S.R.H., and Hartmeyer, I. 2017. Unexpected discovery of 7-methyljuglone (ramentaceone) in several Australian sundews. Carniv. Pl. Newslett. 46: 20-22.

Schlauer, J., Nerz, J., and Rischer, H. 2005. Carnivorous plant chemistry. Acta Botanica Gallica 152: $187-195$.

Zenk, M.H., Fübringer, M., and Steglich, W. 1969. Occurrence and distribution of 7-methyljuglone and plumbagin in the Droseraceae. Phytochemistry 8: 2199-2200.
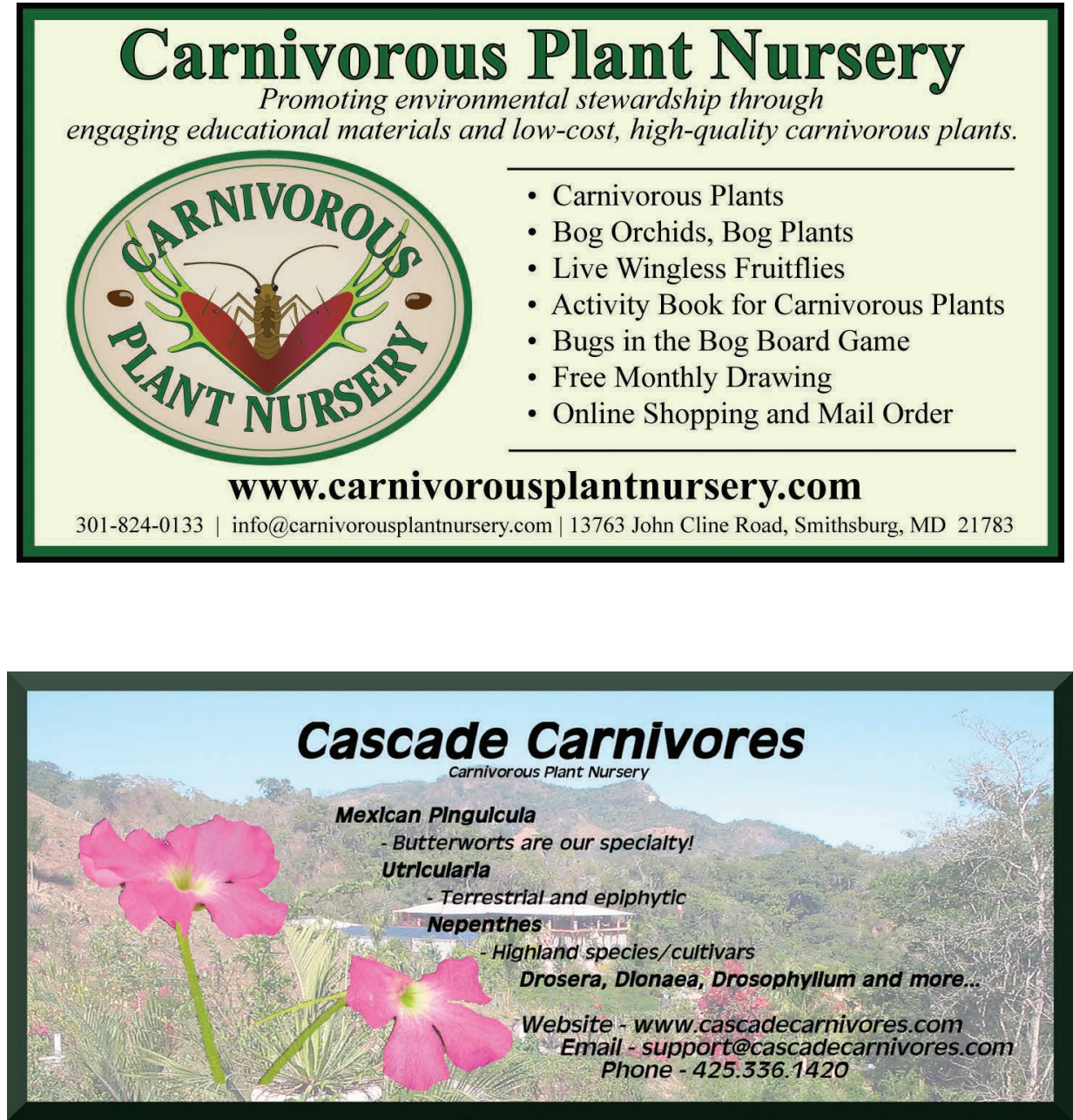